\title{
Short-term effects of ambient fine particulate matter pollution on hospital visits for chronic obstructive pulmonary disease in Beijing, China
}

\author{
Yaohua $\operatorname{Tian}^{\dagger}$, Xiao Xiang ${ }^{\dagger}$, Juan Juan, Jing Song, Yaying Cao, Chao Huang, Man Li and Yonghua Hu*
}

\begin{abstract}
Background: Little is known about the effect of ambient fine particulate matter ( $\mathrm{PM}_{2.5}$ ) on chronic obstructive pulmonary disease (COPD) in China. The objective of this study was to explore the short-term effects of $\mathrm{PM}_{2.5}$ on outpatient and inpatient visits for COPD in Beijing, China.

Methods: A total of 3,503,313 outpatient visits and 126,982 inpatient visits for COPD between January 1, 2010, and June 30, 2012, were identified from the Beijing Medical Claim Data for Employees. A generalized additive Poisson model was applied to estimate the percentage change with 95\% confidence interval (Cl) in hospital visits for COPD in relation to an interquartile range (IQR) $\left(90.8 \mathrm{\mu g} / \mathrm{m}^{3}\right)$ increase in $\mathrm{PM}_{2.5}$ concentrations.

Results: Short-term exposure to $\mathrm{PM}_{2.5}$ was significantly associated with increased use of COPD-related health services. There were clear exposure-response associations of PM 2.5 with COPD outpatient and inpatient visits. An IQR increase in the concurrent day $\mathrm{PM}_{2.5}$ concentrations was significantly associated with a $2.38 \%(95 \% \mathrm{Cl}, 2.22 \%-2$. 53\%) and 6.03\% (95\% Cl, 5.19\%-6.87\%) increase in daily outpatient visits and inpatient visits, respectively. Elderly people were more sensitive to the adverse effects. The estimated risk was higher during the warm season compared to the cool season.
\end{abstract}

Conclusions: Short-term exposure to $\mathrm{PM}_{2.5}$ was associated with increased risk of hospital visits for COPD. Our findings contributed to the limited evidence concerning the effects of ambient PM 2.5 on COPD morbidity in developing countries.

Keywords: COPD, $\mathrm{PM}_{2.5}$, Air pollution, Outpatient visit, Inpatient visit

\section{Background}

Chronic obstructive pulmonary disease (COPD) is a major public health problem that affects more than 300 million people and accounts for an estimated 3.2 million deaths worldwide in 2015 [1, 2]. In China, the number of COPD cases increased from 32.4 million in 1990 to 54.8 million in 2013 [3]. Research has provided compelling evidence linking ambient air pollution to COPD risk [4-8]. Ambient fine particulate matter $\left(\mathrm{PM}_{2.5}\right.$, particulate matter $\leq 2.5 \mu \mathrm{m}$ in aerodynamic diameter) has been

\footnotetext{
* Correspondence: yhhu@bjmu.edu.cn

${ }^{\dagger}$ Equal contributors

Department of Epidemiology and Biostatistics, School of Public Health,

Peking University, No.38 Xueyuan Road, Beijing 100191, China
}

a leading cause of global burden of disease, accounting for an estimated 4.2 million deaths and 103.1 million disability-adjusted life-years in 2015 [9]. A recent metaanalysis that summarized the results from 12 studies using either admission or mortality data indicated that short-term exposure to $\mathrm{PM}_{2.5}$ was significantly associated with increased risk of COPD [10]. However, none of these studies were conducted in developing countries where $\mathrm{PM}_{2.5}$ pollution is generally more severe [11], possibly because of the limited availability of $\mathrm{PM}_{2.5}$ monitoring data. For example, in China, data on $\mathrm{PM}_{2.5}$ level in major Chinese cities were first announced in 2013.

Short-term increase in $\mathrm{PM}_{2.5}$ concentration has been linked to excess daily emergency room visits, hospital 
admissions and mortality due to COPD. However, few studies have been conducted to evaluate the effect of $\mathrm{PM}_{2.5}$ on daily office-based physician visits, mainly because regular outpatient visits in Western countries are scheduled by appointment [12]. In the U.S., in 2000, 8 million visits for COPD were made to physician offices, while there were only 1.5 million emergency department visits, 726,000 hospitalizations and 119,000 deaths for COPD [13, 14]. Therefore, outpatient physician visit could reflect air pollution-related effects in a broader segment of population with its greater coverage [15-17].

China, the largest developing country, has the highest ambient $\mathrm{PM}_{2.5}$ levels worldwide [18]. A general practitioner-based referral system is not available in China [19]. Regular outpatient visits are unscheduled and are on a first-come first-served basis. Hospital outpatient and emergency department visits were estimated to account for $>95 \%$ of total hospital visits in 2014 [17]. Outpatient visit has been used as an important morbidity measure in assessing air pollution-related health effects in China $[15,17,20,21]$. The objective of this study was to explore the short-term effects of $\mathrm{PM}_{2.5}$ on hospital visits for COPD in Beijing, China.

\section{Methods}

\section{Data collection}

Daily counts of hospital visits for COPD were obtained from Beijing Medical Claim Data for Employees. The database records medical claim data for all working or retired employees who are covered by basic medical insurance in Beijing. In order to be reimbursed, a claim for billable medical service must be submitted on a standardized electronic form, which includes data elements such as gender, birthday, the date of hospital visit, discharge diagnosis in Chinese and corresponding International Classification of Diseases, 10th Revision (ICD10) code, and reimbursement information. Daily outpatient and inpatient visits with a primary diagnosis of COPD (ICD-10 codes J40-J44) between January 1, 2010, and June 30, 2012 (a total of 912 days) were extracted from the database. The outpatient visit was defined as a patient visit to a physician's office, clinic, or hospital outpatient department [22]. Patients aged $<18$ years were too few and thus were excluded from this analysis.

Data on hourly $\mathrm{PM}_{2.5}$ concentrations were collected from the reports published by the U.S. embassy, which established an ambient air quality monitoring station on the rooftop of embassy building located in Chaoyang district, Beijing. The location of the monitoring station was shown in the Additional file 1: Figire S1. The $\mathrm{PM}_{2.5}$ levels obtained from the monitor have been demonstrated to exhibit approximately the same trend as citywide $\mathrm{PM}_{2.5}$ levels [23]. To reduce exposure misclassification, the maximum distance between the monitor and hospital visits considered was approximately $40 \mathrm{~km}$ $[24,25]$. Approximately $79.2 \%$ of Beijing's total population lived within a $40-\mathrm{km}$ radius of the monitor. All areas of high population density (>5000 people $/ \mathrm{km}^{2}$ ), $97.8 \%(44 / 45)$ of the tertiary hospitals and $79.3 \%(69 / 87)$ of the secondary hospitals in Beijing located within a 40$\mathrm{km}$ radius of the monitor [26]. Previous studies have indicated that the monitoring data could be used as a proxy for population exposure among individuals living $<40 \mathrm{~km}$ from the monitor [26-28]. The reliability of $\mathrm{PM}_{2.5}$ measurements has been validated in previous studies $[24,26]$. We used daily (24-h) mean concentrations of $\mathrm{PM}_{2.5}$ as a proxy for population exposure level. We also obtained meteorological data on temperature $\left({ }^{\circ} \mathrm{C}\right)$ and relative humidity (\%) during the study period from the Chinese Meteorological Bureau.

\section{Statistical analysis}

We examined the association between $\mathrm{PM}_{2.5}$ and hospital visits for COPD using a generalized additive Poisson model.

$\log \left[\mathrm{E}\left(\mathrm{Y}_{\mathrm{t}}\right)\right]=\alpha+\beta \mathrm{PM}_{2.5}+$ public holiday + day of week $+p s($ calendar time, 6 per year $)+p s($ Temperature, 3$)+$ ps(Relative humidity, 3).

Where, $E\left(Y_{t}\right)$ is the expected daily count of hospital visits for COPD on day $\mathrm{t}$; $p s()$ indicates penalized spline function; public holiday and the day of week were adjusted for as categorical variables; $\beta$ represents logrelative risk of COPD morbidity in relation to unit increase in $\mathrm{PM}_{2.5}$ concentrations. We applied the distributed lag non-linear models with three degrees of freedom $(d f)$ in the penalized splines and a maximum lag of 3 days to control the effects of weather conditions [29]. The $d f$ values for calendar time, temperature, and relative humidity used in this analysis were in line with previous studies $[17,21]$. We also assessed the robustness of the results in terms of the $d f$ values for time trend (4-8 per year), temperature (2-6) and relative humidity (2-6).

Because the assumption of the linearity between $\mathrm{PM}_{2.5}$ level and hospital visits may not be justified, we explored the non-linear exposure-response association using a penalized cubic regression spline of $\mathrm{PM}_{2.5}$ concentration with 3 degrees of freedom. To explore the temporal association between COPD hospital visits and $\mathrm{PM}_{2.5}$, we fitted the models with single-day lag from the current day (lag 0) up to previous 3 days (lag 3). We also estimated associations with 2-day (lag 0-1), 3-day (lag 0-2), and 4-day (lag 0-3) moving average concentrations. We further explored potential effect modification of COPD risk by sex, age (18-64 years and $\geq 65$ years), and season (warm: April to September; cool: October to March) using concurrent day $\mathrm{PM}_{2.5}$ concentration. A penalized spline function of calendar time on warm or cool season was used to accommodate the long-term trend in hospital 
visits for COPD [30, 31]. The statistical significance of subgroup differences were tested using the Z-test [32].

The results were presented as the percentage changes and $95 \%$ confidence intervals (CIs) in daily COPD hospital visits associated with per interquartile (IQR) $\left(90.8 \mu \mathrm{g} / \mathrm{m}^{3}\right)$ increase in $\mathrm{PM}_{2.5}$ concentration. All analyses were conducted in $\mathrm{R}$ Programming Language (V.3.2.2, R Development Core Team) using the " $m g c v$ " and "nlme" packages.

\section{Results}

A summary of basic descriptive information is provided in Table 1. A total of 3,503,313 outpatient visits and 126,982 inpatient visits between January 1, 2010, and June 30, 2012, formed the basis of this study. The mean ages (SD) for outpatient and inpatient visits were 64.3 (12.9) and 71.6 (12.2) years, respectively. For outpatient visits, there were $53.6 \%$ male patients and $51.1 \%$ elderly patients (aged $\geq 65$ years). For inpatient visits, there were $60.1 \%$ male patients and $74.9 \%$ elderly patients. Table 2 shows the distribution of daily hospital visits for COPD, $\mathrm{PM}_{2.5}$ concentration and meteorological variables in Beijing. Over the study period, the daily mean (SD) counts of outpatient and inpatient visits were 3854 (3199) and 44 (31), respectively. The daily mean (SD) $\mathrm{PM}_{2.5}$ concentrations was $99.5(75.3) \mu \mathrm{g} / \mathrm{m}^{3}$. Of the 912 days, only 414 (45.4\%) days of daily $\mathrm{PM}_{2.5}$ concentrations achieved the target of the Chinese Ambient Air Quality Standards Grade II standards $\left(\leq 75 \mu \mathrm{g} / \mathrm{m}^{3}\right)$, and 124 (13.6\%) days achieved the target of WHO Air Quality Guidelines $\left(\leq 25 \mu \mathrm{g} / \mathrm{m}^{3}\right)$. A scatter plot on $\mathrm{PM}_{2.5}$

Table 1 Demographic characteristics of chronic obstructive pulmonary disease (COPD) hospital visits between January 1 , 2010, and June 30, 2012, in Beijing, China

\begin{tabular}{ll}
\hline Variable & No. \\
\hline Outpatient visits & $3,503,313$ \\
$\quad$ Sex & \\
$\quad$ Male (\%) & $1,878,395(53.6)$ \\
$\quad$ Female (\%) & $1,624,918(46.4)$ \\
Age (year) (mean \pm SD) & $64.3 \pm 12.9$ \\
$\quad<65(\%)$ & $1,714,404(48.9)$ \\
$\geq 65(\%)$ & $1,788,909(51.1)$ \\
Inpatient visits & 126,982 \\
Sex & \\
$\quad$ Male (\%) & $76,357(60.1)$ \\
Female (\%) & $50,625(39.9)$ \\
Age (year) (mean \pm SD) & $71.6 \pm 12.2$ \\
$\quad<65(\%)$ & $31,870(25.1)$ \\
$\geq 65$ (\%) & $95,112(74.9)$ \\
\hline
\end{tabular}

concentration and counts of outpatient and inpatient visits was shown in the Additional file 1: Figure S2.

There were clear exposure-response associations of $\mathrm{PM}_{2.5}$ with COPD outpatient and inpatient visits (Fig. 1). Table 3 shows percentage changes in hospital visits associated with an IQR increase in $\mathrm{PM}_{2.5}$ concentration for different lag structures. We observed significant association between $\mathrm{PM}_{2.5}$ and hospital visits after adjustment for calendar time, day of the week, public holiday, and weather conditions. An IQR increase in $\mathrm{PM}_{2.5}$ concentration on the same day corresponded to a $2.38 \%$ (95\% CI, $2.22 \%-2.53 \%)$ and $6.03 \%(95 \%$ CI, 5.19\%-6.87\%) increase in outpatient visits and inpatient visits, respectively. For easy comparisons with other studies under discussion, we have provided a table representing the percentage changes in daily COPD hospital visits associated with per $10 \mu \mathrm{g} / \mathrm{m}^{3}$ increase in $\mathrm{PM}_{2.5}$ concentrations in the Additional file 1: Table S1.

Table 4 shows the estimates of season-, sex- and agespecific effects for $\mathrm{PM}_{2.5}$. In the season-specific analysis, stronger associations were observed in the warm season for both outpatient and inpatient visits. Stronger effects were also observed in the elderly people and females. In the sensitivity analyses by changing the degrees of freedom for calendar time (4-8), temperature (2-6) and relative humidity (2-6), the results remained consistent, indicating that the association between $\mathrm{PM}_{2.5}$ and COPD morbidity obtained from the main models was robust (Table 5).

\section{Discussion}

In this city-wide time-series study, we examined the association between $\mathrm{PM}_{2.5}$ exposure and daily hospital visits for COPD in Beijing. $\mathrm{PM}_{2.5}$ was positively associated with both outpatient and inpatient visit for COPD. There were substantial differences in the effect estimates between inpatient visit and outpatient visit. To the best of our knowledge, this is the first study to examine the differences in the effects of $\mathrm{PM}_{2.5}$ on COPD-attributed outpatient visit and inpatient visit. We found that females and elderly were more vulnerable to the adverse effects of $\mathrm{PM}_{2.5}$. In addition, the risk estimates were higher during the warm season compared to the cool season.

Previously, associations of $\mathrm{PM}_{2.5}$ with emergency department visits or hospital admissions for COPD have been extensively examined in Western countries [4-7]. For example, in a meta-analysis of 12 time-series or case-crossover studies of $\mathrm{PM}_{2.5}$ and daily hospitalizations for COPD, most of which were conducted in Europe and the U.S., Li et al. [10] estimated that the excess change in COPD hospitalizations associated with a $10 \mu \mathrm{g} / \mathrm{m}^{3}$ increase in $\mathrm{PM}_{2.5}$ (lag days $0-7$ ) was $3.1 \%$ (95\% CI: $1.6 \%-4.6 \%)$. Furthermore, a recent meta- 
Table 2 Summary statistics for daily count of chronic obstructive pulmonary disease (COPD) hospital visits, daily fine particulate matter $\left(\mathrm{PM}_{2.5}\right)$ concentrations and weather conditions between January 1, 2010, and June 30, 2012, in Beijing, China

\begin{tabular}{|c|c|c|c|c|c|c|c|}
\hline \multirow[b]{2}{*}{ Variable } & \multirow[b]{2}{*}{ Mean \pm SD } & \multirow[b]{2}{*}{ Minimum } & \multicolumn{3}{|c|}{ Percentile } & \multirow[b]{2}{*}{ Maximum } & \multirow[b]{2}{*}{$\mathrm{IQR}$} \\
\hline & & & 25 th & 50th & 75 th & & \\
\hline Outpatient visits & $3854 \pm 3199$ & 15 & 1326 & 3427 & 5585 & 16,920 & 4259 \\
\hline Inpatient visits & $44 \pm 31$ & 1 & 93 & 131 & 176 & 409 & 83 \\
\hline $\mathrm{PM}_{2.5}\left(\mu \mathrm{g} / \mathrm{m}^{3}\right)$ & $99.5 \pm 75.3$ & 7.2 & 42.5 & 82.8 & 133.3 & 492.8 & 90.8 \\
\hline Temperature $\left({ }^{\circ} \mathrm{C}\right)$ & $12.6 \pm 11.6$ & -12.5 & 1.5 & 14.1 & 23.8 & 34.5 & 22.3 \\
\hline Relative humidity (\%) & $48.6 \pm 20.3$ & 9 & 30 & 48 & 66 & 92 & 36 \\
\hline
\end{tabular}

IQR Interquartile range, SD Standard deviation

analysis of East Asian literature also indicated significant impacts of $\mathrm{PM}_{2.5}$ on COPD morbidity [33]. However, few studies in China have addressed the association of $\mathrm{PM}_{2.5}$ with morbidity risk. A study conducted in two public general hospitals in Jinan city demonstrated that an increase of $10 \mu \mathrm{g} / \mathrm{m}^{3}$ in $\mathrm{PM}_{2.5}$ concentration corresponded to a $1.4 \%(95 \% \mathrm{CI}: 0.7 \%-2.1 \%)$ and $1.5 \%(95 \%$ CI: $0.4 \%-2.6 \%)$ increase in respiratory emergency department visits for the urban and suburban population, respectively [34]. Another study conducted in ten general hospitals in Beijing found that every $10 \mu \mathrm{g} / \mathrm{m}^{3}$ in $\mathrm{PM}_{2.5}$ concentration was significantly associated with a $1.46 \%$ (95\% CI: $0.13 \%-2.79 \%)$ increase in the emergency department visits for acute exacerbation of COPD on the same day [35]. A common limitation of these studies was their restriction to one or several hospitals. The use of a large city-wide population-based database in this study helped ensure the representativeness and generalizability of our findings. Our findings were supported by a recent national study done in 272 cities in

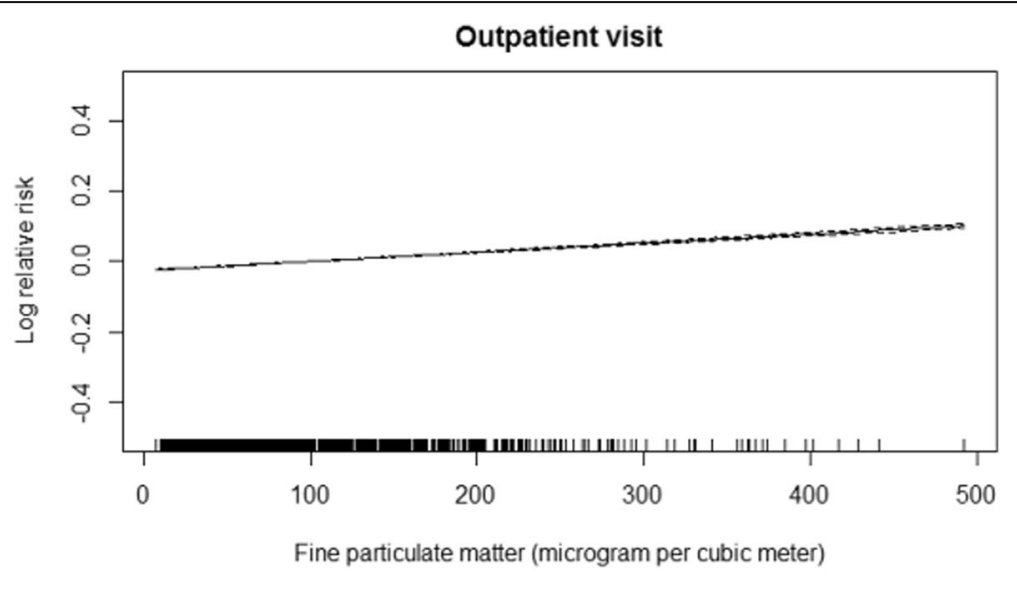

Inpatient visit

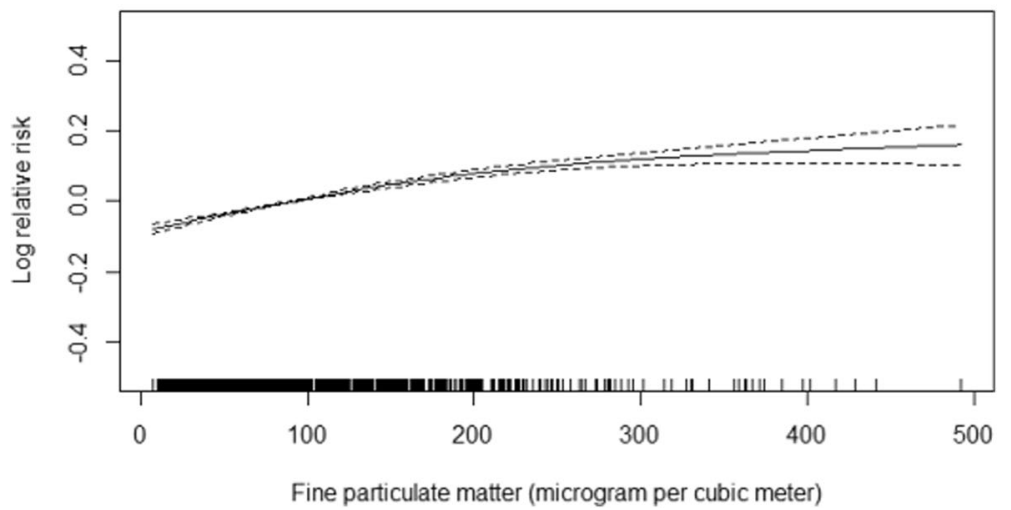

Fig. 1 The concentration-response curves of fine particulate matter $\left(\mathrm{PM}_{2.5}\right)$ concentrations (degree of freedom = 3) and outpatient visits and inpatient visit for chronic obstructive pulmonary disease (COPD) between January 1, 2010, and June 30, 2012, in Beijing, China. Note: The X-axis is the concurrent day $\mathrm{PM}_{2.5}$ concentrations $\left(\mu \mathrm{g} / \mathrm{m}^{3}\right.$ ), Y-axis is the predicted log (relative risk (RR)), is shown by the solid line, and the dotted lines represent the $95 \% \mathrm{Cl}$ 
Table 3 Percentage changes with 95\% Cls in outpatient and inpatient visits for chronic obstructive pulmonary disease (COPD) associated with an interquartile range increases in fine particulate matter $\left(\mathrm{PM}_{2.5}\right)$ concentration $\left(90.8 \mathrm{\mu g} / \mathrm{m}^{3}\right)$ for different lag structures

\begin{tabular}{|c|c|c|c|c|}
\hline Hospital service & Lag days & Percentage change & $95 \% \mathrm{Cl}$ & $P$ \\
\hline \multirow[t]{7}{*}{ Outpatient visits } & Lag 0 days & 2.38 & $2.22-2.53$ & $<2 \mathrm{e}-16$ \\
\hline & Lag 1 days & 0.19 & $0.06-0.33$ & 0.00485 \\
\hline & Lag 2 days & 0.87 & $0.75-1.00$ & $<2 \mathrm{e}-16$ \\
\hline & Lag 3 days & 1.57 & $1.44-1.69$ & $<2 \mathrm{e}-16$ \\
\hline & Lag 0-1 days & 1.62 & $1.44-1.79$ & $<2 \mathrm{e}-16$ \\
\hline & Lag 0-2 days & 1.81 & $1.64-2.00$ & $<2 \mathrm{e}-16$ \\
\hline & Lag 0-3 days & 2.43 & $2.23-2.62$ & $<2 \mathrm{e}-16$ \\
\hline \multirow[t]{7}{*}{ Inpatient visits } & Lag 0 days & 6.03 & $5.19-6.87$ & $<2 \mathrm{e}-16$ \\
\hline & Lag 1 days & 2.41 & $1.69-3.14$ & $4.46 \mathrm{e}-11$ \\
\hline & Lag 2 days & 1.29 & $0.63-1.96$ & 0.000119 \\
\hline & Lag 3 days & 0.21 & $-0.44-0.86$ & 0.527 \\
\hline & Lag 0-1 days & 5.61 & $4.68-6.54$ & $<2 \mathrm{e}-16$ \\
\hline & Lag 0-2 days & 5.06 & $4.09-6.05$ & $<2 \mathrm{e}-16$ \\
\hline & Lag 0-3 days & 4.33 & $3.31-5.36$ & $<2 \mathrm{e}-16$ \\
\hline
\end{tabular}

Table 4 Percentage changes with 95\% Cls in outpatient and inpatient visits for chronic obstructive pulmonary disease (COPD) associated with an interquartile range increases in fine particulate matter $\left(\mathrm{PM}_{2.5}\right)$ concentration $\left(90.8 \mu \mathrm{g} / \mathrm{m}^{3}\right)$ by season, sex and age ${ }^{a}$

\begin{tabular}{|c|c|c|c|}
\hline & Percentage change & $95 \% \mathrm{Cl}$ & $P$-value \\
\hline \multicolumn{4}{|c|}{ Outpatient visits } \\
\hline Season $^{\mathrm{b}}$ & & & $<0.001$ \\
\hline Cool & 2.19 & $1.99-2.40$ & \\
\hline Warm & 2.80 & $2.51-3.09$ & \\
\hline Sex & & & $<0.001$ \\
\hline Male & 2.10 & $1.88-2.31$ & \\
\hline Female & 2.70 & $2.47-2.93$ & \\
\hline Age (year) & & & $<0.001$ \\
\hline$<65$ & 1.41 & $1.18-1.63$ & \\
\hline$\geq 65$ & 3.30 & $3.08-3.53$ & \\
\hline \multicolumn{4}{|c|}{ Inpatient visits } \\
\hline Season $^{b}$ & & & $<0.001$ \\
\hline Cool & 2.96 & $1.91-4.01$ & \\
\hline Warm & 8.35 & $6.76-9.98$ & \\
\hline Sex & & & 0.982 \\
\hline Male & 6.03 & $4.94-7.12$ & \\
\hline Female & 6.01 & $4.69-7.34$ & \\
\hline Age (year) & & & 0.005 \\
\hline$<65$ & 4.21 & $2.61-5.82$ & \\
\hline$\geq 65$ & 6.72 & $5.73-7.71$ & \\
\hline
\end{tabular}

atag 0 concentrations were used

${ }^{\mathrm{b}} \mathrm{Cool}$ season: from October to March; Warm season: from April to September
China that reported significant effects of $\mathrm{PM}_{2.5}$ on mortality [8].

To date, only a very limited number of studies have evaluated the acute effects of air pollution on outpatient visits for COPD. We observed a significant association between $\mathrm{PM}_{2.5}$ and outpatient visits for COPD exacerbations in Beijing. A study in Taiwan demonstrated that outpatient visits for COPD shows positive correlation with $\mathrm{PM}_{2.5}$ [16]. Our findings are also supported by a recent time-series study conducted in a hospital in Dongguan, China, that reported a significant effect of $\mathrm{PM}_{2.5}$, and that an IQR $\left(33.61 \mu \mathrm{g} / \mathrm{m}^{3}\right)$ increase in $\mathrm{PM}_{2.5}$ concentration at lag 0-3 day was associated with a $8.32 \%$ (95\% CI, $0.85 \%-16.33 \%)$ increase in daily outpatient visits for COPD [21]. Similarly, a case-crossover analysis conducted in a hospital in Beijing, demonstrated that each $10 \mu \mathrm{g} / \mathrm{m}^{3}$ increase of $\mathrm{PM}_{2.5}$ concentration on the current day corresponded to $0.1 \%$ (95\% CI: $0 \%, 0.3 \%$ ) increase in daily outpatient visits for acute exacerbation of COPD [36]. As this is the first study in China to demonstrate a significant effect of $\mathrm{PM}_{2.5}$ on outpatient visits for COPD at the city level, future studies are needed to confirm our findings.

The effect estimates for inpatient visits appeared to differ from those for outpatient visits. Our findings are supported by a time-series analysis in Shanghai that reported significant effects of $\mathrm{PM}_{2.5}$ on daily emergency room visits, but not on outpatient visits [37]. Outpatient visits, emergency room visits and hospitalizations are three major types of health service utilization, but also possessed of important disparities. When the concentration of $\mathrm{PM}_{2.5}$ rises, patients with mild or moderate COPD exacerbations usually expect to receive treatment 
Table 5 Percentage changes with 95\% Cls in outpatient and inpatient visits for chronic obstructive pulmonary disease (COPD) associated with an interquartile range increases in fine particulate matter $\left(\mathrm{PM}_{2.5}\right)$ concentration $\left(90.8 \mu \mathrm{g} / \mathrm{m}^{3}\right)$ on the same day, by different degree of freedom ( $d f$ ) for calendar time, temperature, and relative humidity

\begin{tabular}{|c|c|c|c|c|c|}
\hline \multirow[b]{2}{*}{ Variable } & \multirow[b]{2}{*}{$d f$} & \multicolumn{2}{|l|}{ Outpatient visits } & \multicolumn{2}{|l|}{ Inpatient visits } \\
\hline & & Percentage change & $95 \% \mathrm{Cl}$ & Percentage change & $95 \% \mathrm{Cl}$ \\
\hline \multirow[t]{5}{*}{ Calendar time } & 4 & 1.26 & $1.11-1.41$ & 5.30 & $4.47-6.14$ \\
\hline & 5 & 2.38 & $2.22-2.53$ & 6.03 & $5.19-6.87$ \\
\hline & $6^{\mathrm{a}}$ & 2.38 & $2.22-2.53$ & 6.03 & $5.19-6.87$ \\
\hline & 7 & 2.38 & $2.22-2.53$ & 6.03 & $5.19-6.87$ \\
\hline & 8 & 2.37 & $2.21-2.52$ & 6.01 & $5.17-6.86$ \\
\hline \multirow[t]{5}{*}{ Temperature } & 2 & 2.38 & $2.22-2.53$ & 6.03 & $5.19-6.87$ \\
\hline & $3^{\mathrm{a}}$ & 2.38 & $2.22-2.53$ & 6.03 & $5.19-6.87$ \\
\hline & 4 & 2.88 & $2.72-3.04$ & 6.42 & $5.57-7.29$ \\
\hline & 5 & 2.66 & $2.50-2.82$ & 6.52 & $5.67-7.39$ \\
\hline & 6 & 2.33 & $2.17-2.49$ & 6.41 & $5.55-7.27$ \\
\hline \multirow[t]{5}{*}{ Relative humidity } & 2 & 2.38 & $2.22-2.53$ & 6.03 & $5.19-6.87$ \\
\hline & $3^{\mathrm{a}}$ & 2.38 & $2.22-2.53$ & 6.03 & $5.19-6.87$ \\
\hline & 4 & 2.28 & $2.12-2.44$ & 5.89 & $5.05-6.74$ \\
\hline & 5 & 2.25 & $2.09-2.40$ & 5.84 & $5.00-6.68$ \\
\hline & 6 & 2.25 & $2.09-2.41$ & 5.87 & $5.03-6.72$ \\
\hline
\end{tabular}

${ }^{\mathrm{a}}$ The $d f$ value used in this study model

or fill prescription in outpatient department. Subsequently, if the condition was deteriorated or ineffective, they would then be transferred to emergency department or directly to the ward. Therefore, analyzing outpatient visit provides a more comprehensive estimate of the effect of air pollution, especially for mild and moderate exacerbations. The distinct risk estimates on outpatient visit and inpatient visit might be attributable to the difference in the severity of COPD between these two morbidity outcomes. The factors causing the variations of inpatient visit and outpatient visit can be complicating. Future studies are warranted to explore the variations in the effects estimates for different morbidity outcomes.

Exploring the potential effect modifiers is helpful to identify potentially susceptible population and to develop a more accurate targeted intervention. We found that the effects of $\mathrm{PM}_{2.5}$ were significantly greater in the elderly people, which are consistent with previous findings $[6,35,38]$. These evidences suggested that elderly people, especially those presenting with COPD, should limit outdoor activity or wear a face mask outdoors to reduce personal exposure when $\mathrm{PM}_{2.5}$ pollution is severe. This is in line with the protective measures recommended by government [39]. The gender subgroup analysis suggested that females were more susceptible to $\mathrm{PM}_{2.5}$ exposure among outpatient visits, but not among inpatient visits. The gender-specific acute effects of $\mathrm{PM}_{2.5}$ exposure on COPD morbidity were inconsistent in prior studies $[6,10,35]$. In this study, stronger $\mathrm{PM}_{2.5}$ effects were observed in the warm season. Our findings were consistent with several previous studies [40-42], but in conflict with others indicating non-significant seasonal pattern or even greater adverse effects in the cool season [43]. During the warm season, Beijing residents are more likely to go outdoors and open windows; thus, monitored $\mathrm{PM}_{2.5}$ concentrations may be closer to personal exposure. In addition, seasonal differences in air pollutants may also affect the effect estimates. The seasonal variation in effect estimates need to be further investigated.

This study was subject to several limitations. First, the use of $\mathrm{PM}_{2.5}$ concentrations derived entirely from a fixed-site monitoring station as a proxy for personal exposure is expected to lead to exposure misclassification, which may underestimate the effects of air pollution [44]. Another limitation was our inability to explore the independent effect of $\mathrm{PM}_{2.5}$ because data on other air pollutants was not available in this study. Therefore, our results should be cautiously interpreted, and future studies are needed to explore the independent effect of $\mathrm{PM}_{2.5}$ on COPD. Third, this analysis did not take into account several potential confounding factors, e.g., socioeconomic status and daily activities. Finally, we used ambient $\mathrm{PM}_{2.5}$ levels on the day of hospital visits (outpatient and inpatient visits) as individual exposure. This strategy is consistent with previous studies [4, 5, 22, 25]. However, inpatients would be in hospital, being less 
exposed to the ambient $\mathrm{PM}_{2.5}$ concentrations. This exposure measurement error would tend to bias the effect estimates downward [44].

\section{Conclusions}

In conclusion, this study suggests that short-term exposure to ambient $\mathrm{PM}_{2.5}$ may account for increased daily hospital visits for COPD exacerbations in Beijing, China. Among COPD patients, elderly people and females were more sensitive to the air pollution effects. More attention should be paid to these subpopulations.

\section{Additional file}

Additional file 1: Figure S1. The U.S. Embassy in Beijing is shown at the center of the red circle, the radius of which is $40 \mathrm{~km}$. Figure $\mathbf{S 2}$. A scatter plot on $\mathrm{PM}_{25}$ concentrations and counts of outpatient and inpatient visits. TableS1. Percentage changes with $95 \% \mathrm{Cls}$ in outpatient and inpatient visits for chronic obstructive pulmonary disease (COPD) associated with per $10 \mu \mathrm{g} / \mathrm{m}^{3}$ increase in fine particulate matter $\left(\mathrm{PM}_{2.5}\right)$ concentration for different lag structures. (PDF $195 \mathrm{~kb}$ )

\section{Acknowledgments}

Not applicable

\section{Funding}

This work was supported by the Key Project of Natural Science Funds of China [No. 81230066] and the National Natural Science Fund Projects of China [No. 81473043].

\section{Availability of data and material}

The datasets generated and/or analysed during the current study are not publicly available due to confidentiality agreements but are available from the corresponding author on reasonable request.

\section{Authors' contributions}

$\mathrm{YH}$ contributed to the study concept. $\mathrm{YH}$ had full access to all the data in the study and take responsibility for the integrity of the data. YT and XX contributed to the statistical analysis and tables' development of this article. YT, JJ, YC, JS. ML and CH interpreted the findings and drafted the article. All the authors contributed to the critical revision of the article for important intellectual content. All authors read and approved the final manuscript.

\section{Ethics approval and consent to participate}

The present study is considered exempt from institutional review board approval since the data used was collected for administrative purpose without any personal identifiers.

\section{Consent for publication}

Not applicable.

\section{Competing interests}

The authors declare that they have no competing interests.

\section{Publisher's Note}

Springer Nature remains neutral with regard to jurisdictional claims in published maps and institutional affiliations.

Received: 28 November 2017 Accepted: 20 February 2018 Published online: 27 February 2018

\section{References}

1. GBD 2015 Mortality and Causes of Death Collaborators. Global, regional, and national life expectancy, all-cause mortality, and cause-specific mortality for
249 causes of death, 1980-2015: a systematic analysis for the Global Burden of Disease Study 2015. Lancet. 2016;388(10053):1459-544.

2. Lopez-Campos JL, Tan W, Soriano JB. Global burden of COPD. Respirology. 2016;21(1):14-23.

3. Yin P, Wang H, Vos T, Li Y, Liu S, Liu Y, Liu J, Wang L, Naghavi M, Murray CJ, et al. A subnational analysis of mortality and prevalence of COPD in China from 1990 to 2013: findings from the global burden of disease study 2013. Chest. 2016;150(6):1269-80.

4. Peng RD, Chang HH, Bell ML, McDermott A, Zeger SL, Samet JM, Dominici F. Coarse particulate matter air pollution and hospital admissions for cardiovascular and respiratory diseases among Medicare patients. JAMA 2008;299(18):2172-9.

5. Dominici F, Peng RD, Bell ML, Pham L, McDermott A, Zeger SL, Samet JM. Fine particulate air pollution and hospital admission for cardiovascular and respiratory diseases. JAMA. 2006;295(10):1127-34.

6. Li L, Yang J, Song YF, Chen PY, Ou CQ. The burden of COPD mortality due to ambient air pollution in Guangzhou, China. Sci Rep. 2016;6:25900.

7. Li J, Sun S, Tang R, Qiu H, Huang Q, Mason TG, Tian L. major Air pollutants and risk of COPD exacerbations: a systematic review and meta-analysis. Int J Chron Obstruct Pulmon Dis. 2016;11:3079-91.

8. Chen R, Yin P, Meng X, Liu C, Wang L, Xu X, Ross JA, Tse LA, Zhao Z, Kan H, et al. Fine particulate air pollution and daily mortality. A Nationwide analysis in 272 Chinese cities. Am J Respir Crit Care Med. 2017;196(1):73-81.

9. Cohen AJ, Brauer M, Burnett R, Anderson HR, Frostad J, Estep K, Balakrishnan K, Brunekreef B, Dandona L, Dandona R, et al. Estimates and 25-year trends of the global burden of disease attributable to ambient air pollution: an analysis of data from the global burden of diseases study 2015. Lancet. 2017;10(17):30505-6

10. Li MH, Fan LC, Mao B, Yang JW, Choi AM, Cao WJ, Short-term Exposure XJF. To ambient fine particulate matter increases hospitalizations and mortality in COPD: a systematic review and meta-analysis. Chest. 2016;149(2):447-58.

11. Cohen AJ, Brauer M, Burnett R, Anderson HR, Frostad J, Estep K, Balakrishnan K, Brunekreef B, Dandona L, Dandona R, et al. Estimates and 25-year trends of the global burden of disease attributable to ambient air pollution: an analysis of data from the global burden of diseases study 2015. Lancet. 2017:389(10082):1907-18.

12. Cayirli T, Veral E. Outpatient scheduling in health care: a review of literature. Prod Oper Manag. 2003;12(4):519-49.

13. Mannino DM, Homa DM, Akinbami LJ, Ford ES, Redd SC. Chronic obstructive pulmonary disease surveillance-United States, 1971-2000. Respir Care. 2002;76(10):1184-99.

14. Pauwels RA, Rabe KF. Burden and clinical features of chronic obstructive pulmonary disease (COPD). Lancet. 2004;364(9434):613-20.

15. Xu X, Li B, Huang H. Air pollution and unscheduled hospital outpatient and emergency room visits. Environ Health Perspect. 1995;103(3):286-9.

16. Wang KY, Chau $\Pi$. An association between air pollution and daily outpatient visits for respiratory disease in a heavy industry area. PLoS One. 2013;8(10):e75220

17. Liu Y, Xie S, Yu Q, Huo X, Ming X, Wang J, Zhou Y, Peng Z, Zhang H, Cui X, et al. Short-term effects of ambient air pollution on pediatric outpatient visits for respiratory diseases in Yichang city, China. Environ Pollut. 2017;227:116-24.

18. Kan H, Chen R, Tong S. Ambient air pollution, climate change, and population health in China. Environ Int. 2012;42:10-9.

19. Li Q, Xie P. Outpatient workload in China. Lancet. 2013 Jun 8;381(9882): 1983-4. https://doi.org/10.1016/S0140-6736(13)61198-8.

20. Cao J, Li W, Tan J, Song W, Xu X, Jiang C, Chen G, Chen R, Ma W, Chen B, et al. Association of ambient air pollution with hospital outpatient and emergency room visits in shanghai, China. Sci Total Environ. 2009;407(21): 5531-6.

21. Zhao Y, Wang S, Lang L, Huang C, Ma W, Lin H. Ambient fine and coarse particulate matter pollution and respiratory morbidity in Dongguan, China. Environ Pollut. 2017;222:126-31.

22. Pan HH, Chen CT, Sun HL, Ku MS, Liao PF, Lu KH, Sheu JN, Huang JY, Pai JY, Lue $\mathrm{KH}$. Comparison of the effects of air pollution on outpatient and inpatient visits for asthma: a population-based study in Taiwan. PLoS One. 2014;9(5):e96190.

23. Wang JF, Hu MG, Xu CD, Christakos G, Zhao Y. Estimation of citywide air pollution in Beijing. PLoS One. 2013;8(1):8.

24. Tian Y, Xiang X, Wu Y, Cao Y, song J, sun K, Liu H, Hu Y. Fine particulate air pollution and first hospital admissions for ischemic stroke in Beijing, China. Sci Rep. 2017;7(1):017-04312. 
25. Tian Y, Xiang X, Juan J, Sun K, Song J, Cao Y, Hu Y. Fine particulate air pollution and hospital visits for asthma in Beijing, China. Environ Pollut. 2017;230:227-33

26. Xie W, Li G, Zhao D, Xie X, Wei Z, Wang W, Wang M, Liu W, Sun J, Jia Z, et al. Relationship between fine particulate air pollution and ischaemic heart disease morbidity and mortality. Heart. 2015;101(4):257-63.

27. Wellenius GA, Burger MR, Coull BA, Schwartz J, Suh HH, Koutrakis P, Schlaug G, Gold DR, Mittleman MA. Ambient air pollution and the risk of acute ischemic stroke. Arch Intern Med. 2012;172(3):229-34.

28. Dockery DW, Luttmann-Gibson H, Rich DQ, Link MS, Mittleman MA, Gold DR, Koutrakis P, Schwartz JD, Verrier RL. Association of air pollution with increased incidence of ventricular tachyarrhythmias recorded by implanted cardioverter defibrillators. Environ Health Perspect. 2005;113(6):670-4.

29. Goldberg MS, Gasparrini A, Armstrong B, Valois MF. The short-term influence of temperature on daily mortality in the temperate climate of Montreal, Canada. Environ Res. 2011;111(6):853-60.

30. Yin P, Chen R, Wang L, Meng X, Liu C, Niu Y, Lin Z, Liu Y, Liu J, Qi J, et al. Ambient ozone pollution and daily mortality: a Nationwide study in 272 Chinese cities. Environ Health Perspect. 2017;125(11):117006.

31. Tian Y, Xiang X, Juan J, Song J, Cao Y, Huang C, Li M, Hu Y. Short-term effect of ambient ozone on daily emergency room visits in Beijing. China Sci Rep. 2018:8(1):018-21154.

32. Altman DG, Bland JM. Interaction revisited: the difference between two estimates. BMJ. 2003;326(7382):219.

33. Zhang S, Li G, Tian L, Guo Q, Pan X. Short-term exposure to air pollution and morbidity of COPD and asthma in east Asian area: a systematic review and meta-analysis. Environ Res. 2016;148:15-23.

34. Liu P, Wang X, Fan J, Xiao W, Wang Y. Effects of air pollution on hospital emergency room visits for respiratory diseases: urban-suburban differences in eastern China. Int J Environ Res Public Health. 2016;13(3):341.

35. Xu Q, Li X, Wang S, Wang C, Huang F, Gao Q, Wu L, Tao L, Guo J, Wang W, et al. Fine particulate air pollution and hospital emergency room visits for respiratory disease in urban areas in Beijing, China, in 2013. PLoS One. 2016; 11(4):e0153099.

36. Li R, Jiang N, Liu Q, Huang J, Guo X, Liu F, Gao Z. Impact of air pollutants on outpatient visits for acute respiratory outcomes. Int J Environ Res Public Health. 2017;14(1):47.

37. Wang X, Chen R, Meng X, Geng F, Wang C, Kan H. Associations between fine particle, coarse particle, black carbon and hospital visits in a Chinese city. Sci Total Environ. 2013;460:1-6.

38. Qiu H, Tian LW, Pun VC, Ho KF, Wong TW, Yu IT. Coarse particulate matter associated with increased risk of emergency hospital admissions for pneumonia in Hong Kong. Thorax. 2014;69(11):1027-33.

39. Guan WJ, Zheng XY, Chung KF, Zhong NS. Impact of air pollution on the burden of chronic respiratory diseases in China: time for urgent action. Lancet. 2016:388(10054):1939-51.

40. Tsai SS, Chang CC, Yang CY. Fine particulate air pollution and hospital admissions for chronic obstructive pulmonary disease: a case-crossover study in Taipei. Int J Environ Res Public Health. 2013;10(11):6015-26.

41. Zanobetti A, Franklin M, Koutrakis P, Schwartz J. Fine particulate air pollution and its components in association with cause-specific emergency admissions. Environ Health. 2009;8(58):8-58.

42. Peel JL, Tolbert PE, Klein M, Metzger KB, Flanders WD, Todd K, Mulholland $J A$, Ryan PB, Frumkin H. Ambient air pollution and respiratory emergency department visits. Epidemiology. 2005;16(2):164-74.

43. Ko FW, Tam W, Wong TW, Chan DP, Tung AH, Lai CK, Hui DS. Temporal relationship between air pollutants and hospital admissions for chronic obstructive pulmonary disease in Hong Kong. Thorax. 2007;62(9):780-5.

44. Goldman GT, Mulholland JA, Russell AG, Strickland MJ, Klein M, Waller LA, Tolbert PE. Impact of exposure measurement error in air pollution epidemiology: effect of error type in time-series studies. Environ Health. 2011;10(61):10-61.

\section{Submit your next manuscript to BioMed Central and we will help you at every step:}

- We accept pre-submission inquiries

- Our selector tool helps you to find the most relevant journal

- We provide round the clock customer support

- Convenient online submission

- Thorough peer review

- Inclusion in PubMed and all major indexing services

- Maximum visibility for your research

Submit your manuscript at www.biomedcentral.com/submit

) Biomed Central 